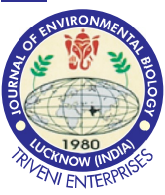

\title{
Pathogenicity and population dynamics of foliar nematode, Aphelenchoides besseyi infecting tuberose in West Bengal, India
}

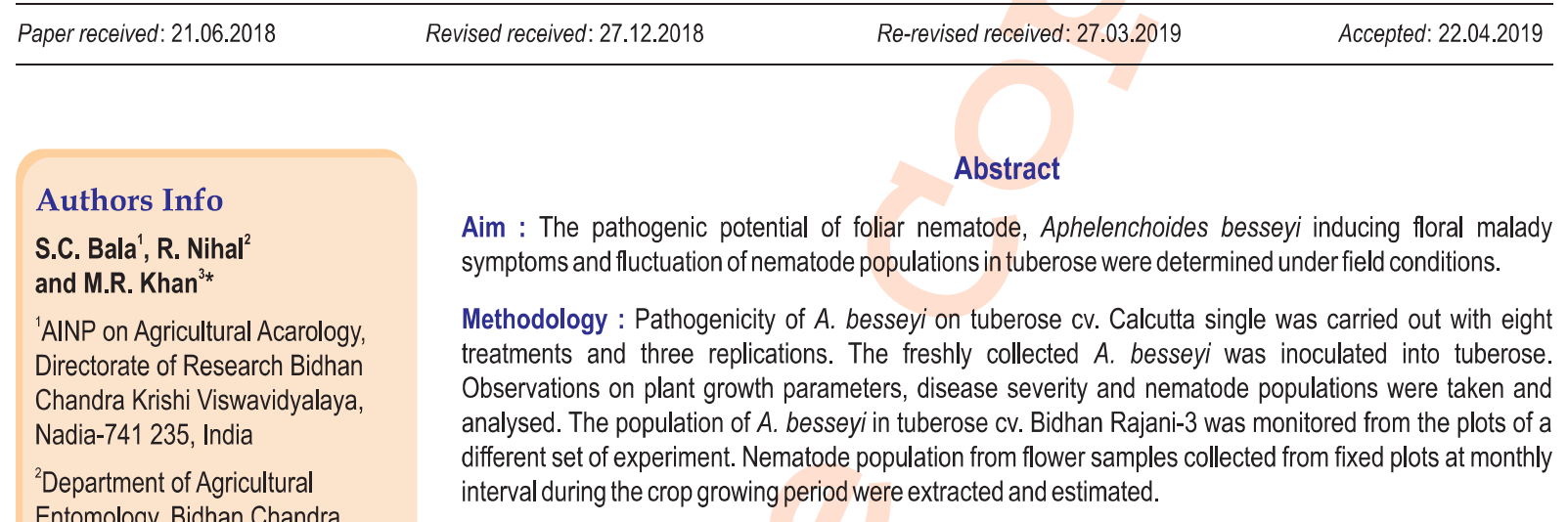

Entomology, Bidhan Chandra

Krishi Viswavidyalaya,

Nadia-741 235, India

${ }^{3}$ Division of Nematology, ICARIndian Agricultural Research Institute, New Delhi-110 012, India

${ }^{*}$ Corresponding Author Email : drmrkhanbckv@gmail.com

\section{Edited by \\ Dr. Gundappa}

\section{Reviewed by}

Dr. L.N. Mahawer

Dr. Raman Kumar Walia

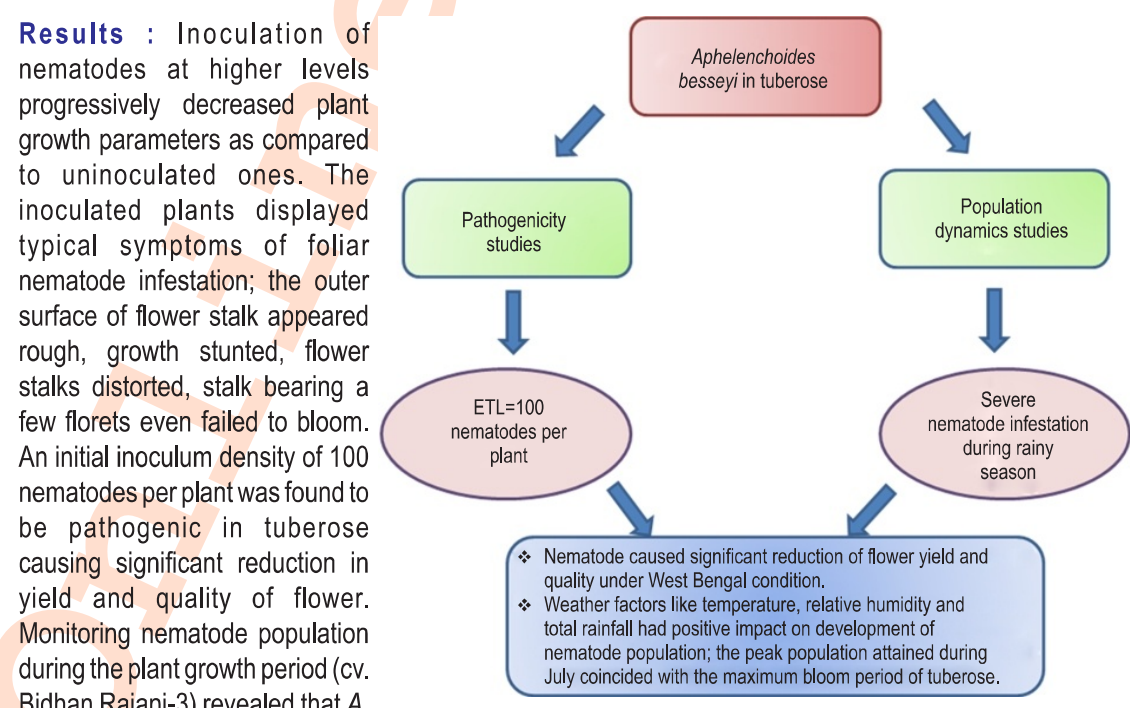
Bidhan Rajani-3) revealed that $A$.

besseyi maintained maximum population during rainy season coinciding with the start of heavy flush of tuberose and minimum during December to February.

Interpretation : An initial inoculum density of $100 \mathrm{~A}$. besseyi per plant was considered pathogenic to tuberose. The nematode population attained peak density during July when the air temperature, relative humidity and total rainfall remained fairly high and lowest during February to December.

Key words: Foliar nematode, Pathogenicity, Population fluctuation, Tuberose

How to cite : Bala, S.C., R. Nihal and M.R. Khan: Pathogenicity and population dynamics of foliar nematode, Aphelenchoides besseyi infecting tuberose in West Bengal, India. J. Environ. Biol., 40, 1159-1163 (2019). http://doi.org/10.22438/jeb/40/6/MRN-946 


\section{Introduction}

Tuberose (Polianthes tuberosa L.) is a bulbous ornamental plant commercially cultivated in many states of India, including West Bengal. West Bengal shares maximum acreage of 6000 ha and occupies first position in respect of area and production. Many plant parasitic nematodes like Aphelenchoides besseyi, Meloidogyne incognita, M. javanica, Rotylenchulus reniformis, Helicotylenchus spp. Tylenchorhynchus mashhoodi and Hoplolaimus indicus, etc., are associated with tuberose rhizosphere (Saha and Khan, 2016, Khan and Pal, 2001). The foliar nematode, $A$. besseyi is of serious concern. The infection of nematode species induces a floral malady symptom in tuberose (Chakraborti and Ghosh, 1993). This nematode species can cause yield loss up to 59\% (Pathak and Khan, 2009) and has been considered as a key pest of tuberose (Khan et al., 2012). Infestation of foliar nematode in West Bengal is a potential threat for its profitable cultivation; the area under tuberose cultivation started declining on account of severe infestation of foliar nematode on the traditional cultivars like Calcutta Single and Calcutta Double. This nematode can easily disperse by means of infested bulb, irrigation water and farm implements. Holtzmann (1968) first reported this nematode in leaves of tuberose from the Hawaii Islands and further reported from Ranaghat region in West Bengal (Chakraborti and Ghosh, 1993) and in Odisha (Das et al., 2011) and Mekon delta of Vietnam (Cuc et al., 2010). The occurrence of floral malady in tuberose has been investigated for its pathogenicity by Das et al. (2011). The population fluctuation of A. besseyi in tuberose cultivar cv. Calcutta Single was noted (Bala et al., 2016; Khan and Ghosh, 2011; Das and Swain, 2013), however, there is a gap in the current knowledge on the pathogenic level of $A$. besseyi inducing floral malady symptoms in tuberose (cv. Calcutta Single)and population of foliar nematode infecting tuberose (cv. Bidhan Rajani -3). Therefore, the present investigation was carried out to determine the pathogenicity and population fluctuation of foliar nematode in tuberose.

\section{Materials and Methods}

A field experiment for evaluating the pathogenicity of foliar nematode in tuberose was conducted at the Directorate of Research Complex, Bidhan Chandra Krishi Viswavidyalaya (BCKV), Kalyani, Nadia for two consecutive years (2015-2017) with tuberose cultivar Calcutta Single. Bulbs $(2.0-2.5 \mathrm{~cm}$ diameter) of tuberose were collected from farmer's fields, soaked overnight in plain water followed by hot-water treatment at $52^{\circ} \mathrm{C}$ for $30 \mathrm{~min}$ (Khan et al., 2005) for disinfection of nematode. The disinfected bulbs were planted in the plot at a spacing of 20X20 $\mathrm{cm}$. There were eight treatments; each treatment was replicated three times in a Randomized Block Design. After sprouting of planted bulbs, freshly collected $A$. besseyi nematode suspension were inoculated into the plant with the help of a dispenser (without a needle) as per treatment schedule: $T_{1}=0$ nematode per plant (Untreated control), $T_{2}=10$ nematodes per plant, $T_{3}=100$ nematodes per plant, $T_{4}=500$ nematodes per plant, $T_{5}=1,000$ nematodes per plant, $T_{6}=2,500$ nematodes per plant, $T_{7}=5,000$ nematodes per plant and $T_{8}=10,000$ nematodes per plant, respectively. The plants receiving zero nematode served as untreated control. The observations on severity of disease and plant growth parameters viz., stalk length $(\mathrm{cm})$, spike length $(\mathrm{cm})$, number of floret/spike, disease infested stalk and nematode population per $10 \mathrm{~g}$ flower were recorded. The incidence of nematode disease in tuberose was recorded on a $0-4$ scale where 0 is no malady symptom on flower stalk, 1 is distortion at basal parts of flower stalk but exhibit flower bloom, 2 is entire flower stalk exhibit distortions but few flowers bloom at the tip, 3 is entire flower stalk distorted but with no flower bloom and 4 is complete sterility of flower stalk or blind head (Khan, 2004). All data obtained in the study were analyzed by RBD analysis with MSTAT-C computer software.

The population of $A$. besseyi in tuberose was monitored from a different set of experiment at the same site; the tuberose cultivar Bidhan Rajani-3 (a susceptible cultivar) was grown in plots. The flower samples were collected randomly from fixed plots at monthly interval during growing period. The nematode population was extracted from the flower stalks; the flowers were chopped into small pieces with the help of a sharp knife, soaked on a wire-gauge fitted assembly over a Petri plate containing clean water in such a manner that the bottom of wire-gauge just touched water below. The wire-gauge assembly was covered by another Petri plate to prevent water loss and kept undisturbed for $12 \mathrm{hrs}$. The nematode suspension was then passed through sieves 20 and 400 mesh serially (20 mesh placed over 400 mesh). The final population was counted with the help of a multichambered counting disc under stereoscopic binocular microscope. All data obtained in the study was analyzed by correlation and regression analysis in MSTAT-C computer software. The weather data during the period of experiment (January-December, 2016) was collected from the nearest observatory of All India Coordinated Research project on Agrometeorology, Kalyani Centre, BCKV, West Bengal.

\section{Results and Discussion}

Experimental results revealed a progressive decrease of all plant growth components in the inoculated plants as compared to plants which were not inoculated. It was evident from the result that disease infestation (scale 0-4) and nematode population was quite high in inoculated plants (Table 1). However, the treatments $T_{7}$ and $T_{8}$ recorded maximum infestation and more number of nematode populations per $10 \mathrm{~g}$ of flower because of higher concentration of initial inoculums. Nematode infected stalk appeared rough, crinkled and distorted and in severe form of infestation flowers failed to open and some stalks produced blind head. Moreover, infection of nematodes affected quality of flowers; infected flowers developed brownish spots on leave and petal which subsequently turned into rusty brown spots, anthers appeared blackish in colour and the spike appeared less attractive. Similar symptoms on tuberose were observed earlier (Chakraborti and Ghosh, 1993; Das et al., 2011; Khan et al., 2012) due to infection of $A$. besseyi on Calcutta Single as well as 
Table 1: Effects of different treatments of foliar nematode (A. besseyi) on yield, disease infestation and nematode population in tuberose cultivar Calcutta Single (pooled data)

\begin{tabular}{llllll}
\hline $\begin{array}{l}\text { Treatment } \\
\text { (inoculums level) }\end{array}$ & $\begin{array}{l}\text { Stalk length } \\
(\mathbf{c m})\end{array}$ & $\begin{array}{l}\text { Spike length } \\
(\mathbf{c m})\end{array}$ & $\begin{array}{l}\text { Number of } \\
\text { floret/spike }\end{array}$ & $\begin{array}{l}\text { Mean of disease infested } \\
\text { stalk (scale 0-4) }\end{array}$ & $\begin{array}{l}\text { Nematode population } \\
\text { per 10 g flowers }\end{array}$ \\
\hline $\mathrm{T}_{1}$ & $110.42 \pm 8.47$ & $37.75 \pm 7.77$ & $26.82 \pm 5.63$ & 0.0 & 0.0 \\
& $(10.51)^{*}$ & $(6.14)$ & $(5.16)$ & & $18.9 \pm 16.17$ \\
$\mathrm{~T}_{2}$ & $106.74 \pm 6.91$ & $34.70 \pm 6.10$ & $24.72 \pm 4.16$ & $1.02 \pm 0.40$ & $(4.34)$ \\
& $(10.33)$ & $(5.89)$ & $(4.78)$ & & $54.60 \pm 29.28$ \\
$\mathrm{~T}_{3}$ & $90.18 \pm 7.74$ & $27.20 \pm 4.75$ & $20.53 \pm 4.37$ & $1.16 \pm 0.37$ & $(7.38)$ \\
& $(9.49)$ & $(5.21)$ & $(4.53)$ & & $57.51 \pm 38.06$ \\
$\mathrm{~T}_{4}$ & $85.02 \pm 6.47$ & $23.04 \pm 3.34$ & $16.49 \pm 5.50$ & $1.84 \pm 0.54$ & $(7.58)$ \\
& $(9.22)$ & $(4.80)$ & $(4.07)$ & & $76.65 \pm 34.15$ \\
$\mathrm{~T}_{5}$ & $75.61 \pm 8.46$ & $21.05 \pm 3.66$ & $13.47 \pm 5.47$ & $2.02 \pm 0.63$ & $(8.75)$ \\
& $(8.69)$ & $(4.58)$ & $(3.67)$ & & $99.77 \pm 57.20$ \\
$\mathrm{~T}_{6}$ & $71.26 \pm 9.74$ & $16.98 \pm 3.52$ & $11.63 \pm 6.60$ & $2.47 \pm 0.53$ & $(9.99)$ \\
& $(8.44)$ & $(4.12)$ & $(3.46)$ & & $129.47 \pm 62.08$ \\
$\mathrm{~T}_{7}$ & $62.11 \pm 10.76$ & $12.16 \pm 3.74$ & $8.82 \pm 6.08$ & $2.82 \pm 0.38$ & $(11.37)$ \\
& $(7.88)$ & $(3.48)$ & $(2.96)$ & & $131.07 \pm 41.40$ \\
$\mathrm{~T}_{8}$ & $41.49 \pm 11.40$ & $6.04 \pm 3.03$ & $4.30 \pm 2.84$ & $3.62 \pm 0.46$ & $(11.44)$ \\
$\mathrm{S} . \mathrm{Em} . \pm$ & $(6.44)$ & $(2.45)$ & $(2.07)$ & & 1.36 \\
$\mathrm{CD}(\mathrm{P}=0.05)$ & 2.03 & 1.82 & 0.83 & 0.37 & 9.37 \\
\hline
\end{tabular}

*Values in parentheses are square root transformed values; $T_{1}=$ Untreated control, $T_{2}=10$ nematodes inoculated per plant, $T_{3}=100$ nematodes inoculated per plant, $T_{4}=500$ nematodes inoculated per plant, $T_{5}=1000$ nematodes inoculated per plant, $T_{6}=2500$ nematodes inoculated per plant, $\mathrm{T}_{7}=5000$ nematodes inoculated per plant and $\mathrm{T}_{8}=10000$ nematodes inoculated per plant

Table 2 : Correlation and regression coefficient of foliar nematode, Aphelenchoides besseyi in tuberose with weather factors during 2016

\begin{tabular}{lll}
\hline Weather parameters & Correlation $(r)$ & Regression equation \\
\hline Max. temperature $\left({ }^{\circ} \mathrm{C}\right)$ & 0.43 & $\mathrm{y}=-4.5535 \mathrm{x}^{2}+321 \mathrm{x}-5266.6 \mathrm{R}^{2}=0.1815$ \\
Min. temperature $\left({ }^{\circ} \mathrm{C}\right)$ & -0.75 & $\mathrm{y}=7.8627 \mathrm{x}^{2}-269.52 \mathrm{x}+2246.3 \mathrm{R}^{2}=0.5689$ \\
Relative humidity $(\%)$ & 0.76 & $\mathrm{y}=0.4857 \mathrm{x}^{2}-46.928 \mathrm{x}+1215 \mathrm{R}^{2}=0.5836$ \\
Total rainfall $(\mathrm{mm})$ & 0.78 & $\mathrm{y}=-0.0056 \mathrm{x}^{2}+3.8425 \mathrm{x}+8.9218 \mathrm{R}^{2}=0.6207$ \\
Bright sunshine hours & -0.69 & $\mathrm{y}=89.104 \mathrm{x}^{2}-1135.7 \mathrm{x}+3695.9 \mathrm{R}^{2}=0.4853$ \\
\hline
\end{tabular}

in Calcutta Double. The results of this study revealed that application of higher level of inoculums during bulb sprouting stage severely affected the quality of flower production.

Two year pooled data exhibited maximum stalk length in $T_{1}$ and $T_{2}$ treated plants $(110.42 \mathrm{~cm})$ and $(106.74 \mathrm{~cm})$ while the minimum stalk length was noted in $T_{8}(41.49 \mathrm{~cm})$. Plants receiving $T_{1}$ treatment produced largest size $(37.75 \mathrm{~cm})$ of spike followed by $T_{2}(34.70 \mathrm{~cm})$ whereas the smallest size of spike was found in $T_{8}$ $(6.04 \mathrm{~cm})$. Similarly least number of florets per spike was recorded in $T_{8}(4.30)$ followed by $T_{7}(8.82)$. As the results of $T_{1}$ and $\mathrm{T}_{2}$ with respect to stalk length, spike length and number of florets were not significantly different. Therefore, an initial inoculum density of 100 nematodes per plant was considered pathogenic to tuberose; this population level can cause significant reduction of stalk length, spike length, number of florets as well as overall flower yield. The present finding is in accordance with Das et al. (2011) who reported that infestation of foliar nematode causes leaf tip to dry followed by withering, rolling of leave tips, stunted growth and stalk bearing few number of florets. Furthermore, relatively low population of $A$. besseyi was recovered from the infested flower stalks in $T_{1}$ and $T_{2}$ and the number increased with increase in inoculum levels and the maximum number of nematode were recovered from treatment $T_{7}$ and $T_{8}$. This was quite interesting that nematode did not face any competition for feeding, space and sources, therefore, the is population multiplied even at highest level of inoculum $(10,000$ nematodes per plant). Infection of foliar nematode in tuberose affects quality 


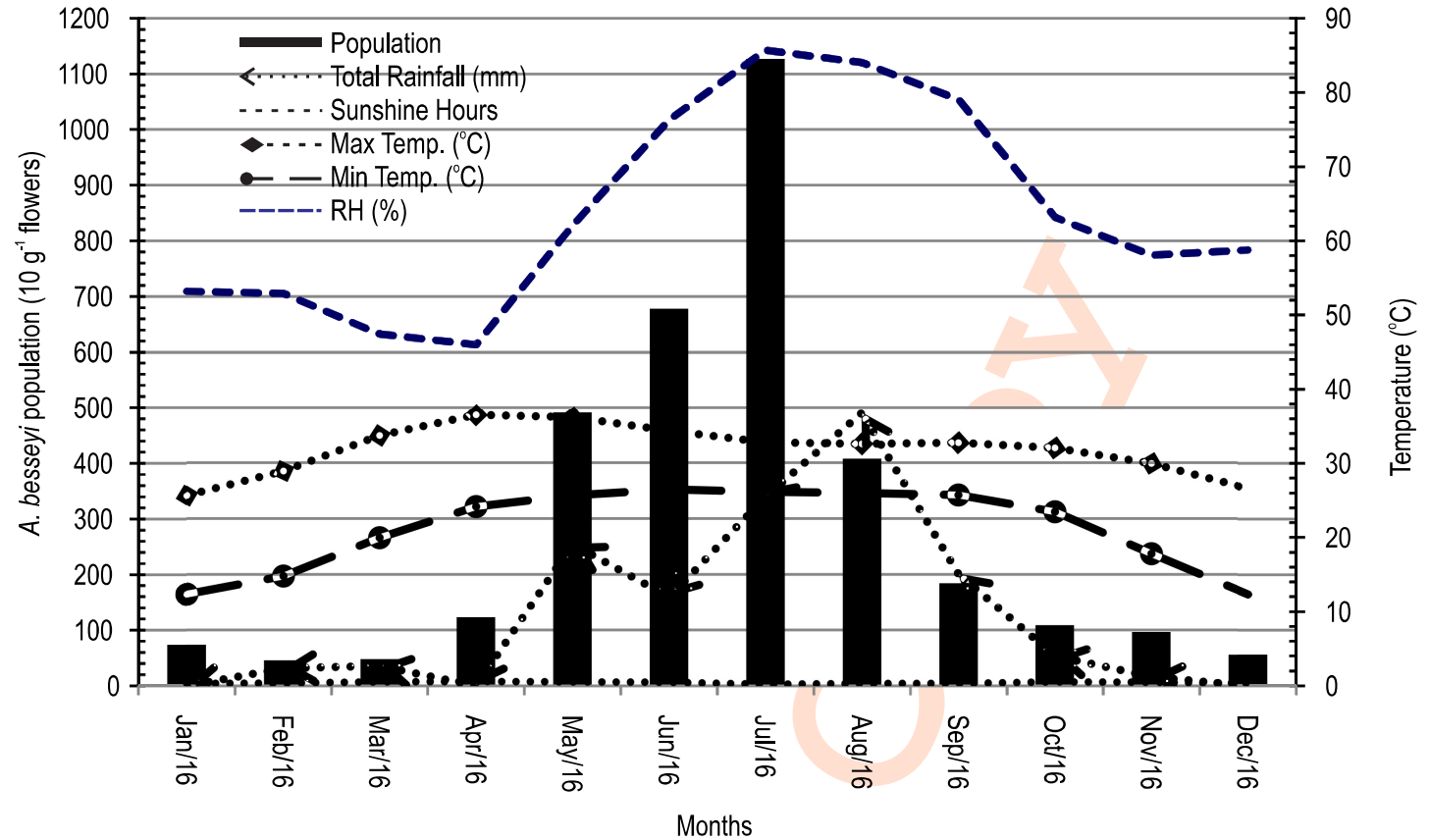

Fig.1: Population fluctuation of Aphelenchoides besseyi infecting tuberose (cv. Bidhan Rajani-3).

of flowers and minimum 100 nematodes is are enough for deteriorating of quality of flower. Previous studies have (Khan, 2004; Khan, 2006) confirmed that the infested flowers harbour large number of nematodes, and severely affected the flower stalks, dries up and nematode survive in coiled anhydrobiotic state for survival and dissemination (Khan, 2004; Khan et al., 2012).

Foliar nematode ( $A$. besseyi) is mainly affected by variation in weather factors viz., temperature, relative humidity and total rainfall. During the study period, the nematode population showed fluctuation in numbers; they were recorded between 46 to1127 per $10 \mathrm{~g}$ of flowers (Fig.1). However, the lowest population was recorded during December to February (46 - 74 per $10 \mathrm{~g}$ flower). Further, the population gradually increased and attained peak density in the month of July (1127 per $10 \mathrm{~g}$ flowers) when air temperature, relative humidity and total rainfall remained fairly high (Fig.1). Infestation of this nematode was found high during rainy season; the period coinciding with heavy flush of tuberose. In fact, $A$. besseyi is an ecto-endoparasite and primarily depends on moisture and temperature for its spread and rapid multiplication. This study demonstrates the fact that foliar nematode population exhibit positive correlation at maximum temperature, relative humidity and total rainfall while negative correlation at minimum temperature and bright sunshine hours (Table 2). This was further evident from the observation made during winter season in West Bengal; the least population of $A$. besseyi was observed during winter season when temperature and relative humidity were relatively low. The decline in nematode population during September-November was primarily due to senescence of tuberose plants. Khan and Ghosh (2011) and Bala et al. (2016) also reported maximum foliar nematode population on Calcutta Single during July to November, while Das and Swain (2013) recorded maximum population on Calcutta Single from July to September. Therefore, the present finding further confirmed dynamics of $A$. besseyi infecting tuberose cv. Bidhan Rajani-3 with slight variations which could be attributed to climate change, growth conditions and cultivars.

The study demonstrated that foliar nematode becomes pathogenic at an initial 100 nematodes per plant in tuberose (cv Calcutta single) and the nematode maintains maximum population during July month and minimum during December to February. These findings could be useful for development of foliar nematode management strategies in tuberose.

\section{Acknowledgment}

Authors thank Professor R. Sadhukhan, Department of Genetic and Plant Breeding, Bidhan Chandra Krishi Viswavidyalaya, Mohanpur, Nadia, West Bengal for providing support and help for carrying out this study.

\section{References}

Bala, S.C., M.R. Khan and A.K. Mukhopadhyay: Population dynamic and survival of foliar nematode (Aphelenchoides besseyi) on tuberose 
in field. Indian J. Nematol., 46, 97-101(2016).

Chakraborti, H.S. and S.C. Ghosh: Studies on the floral malady of Polianthes tuberosa L., J. Mycopathol. Res., 33, 109-115(1993).

Cuc, N.T.T., N.T. Son, T. M. Trung, N.V. Trang, L.M. Dang and M. Pilon: Hot-water treatment prevents Aphelenchoides besseyi damage to Polianthes tuberosa crops in the Mekong Delta of Vietnam. Crop Protec., 29, 599-602 (2010).

Das, N. and P.K. Swain: Population dynamics of foliar nematode, Aphelenchoides besseyi infecting tuberose. Indian J. Nematol., 43, 210-237 (2013)

Das, N., P.K. Swain and U.K. Nanda: Pathogenicity of foliar nematode, Aphelenchoides besseyi in tuberose. J. Plant. Prot. Environ., 8, 97 99 (2011).

Holtzmann, O.V.: A foliar disease of tuberose causer by Aphelenchoides besseyi. Plant Dis. Reptr., 52, 56 (1968).

Khan, M.R. and A.K. Pal: Plant parasitic nematodes associated with tuberose (Polianthes tuberosa L.) in West Bengal. Ann. Plant. Protec. Sci., 9, 357-359 (2001).

Khan, M.R. and S. Ghosh : Survival and population dynamics of foliar nematode, Aphelenchoides besseyi infecting tuberose in West
Bengal, India. Indian J. Nematol., 41, 47-51(2011).

Khan, M.R.: Observation on foliar nematode, Aphelenchoides besseyi in tuberose (Polianthes tuberosa L.) in West Bengal. Ann. Plant. Protec. Sci., 12, 106-109 (2004).

Khan, M.R.: Current options for managing nematode pest of crops in India. In: Plant Nematology in India (Eds.: N. Mohilal and R.K. Gambhir), pp. 16-50 (2006)

Khan, M.R., Z.A. Handoo, Uma Rao, S.B. Rao and J.S. Prasad: Observation on the foliar nematode, Aphelenchoides besseyi, infecting tuberose and rice in India. J. Nematol., 44, 399-406 (2012).

Khan, M. R., S. Shit, A.K. Pal and B. Biswas: Integrated approach for management of foliar nematode, Aphelenchoides besseyi in West Bengal, India. Int. J. Nematol., 15, 30-34 (2005)

Pathak, B. and M.R. Khan: Yield loss potential of foliar nematode, Aphelenchoides besseyi in tuberose. Indian J. Nematol., 39, 38-40 (2009).

Saha, T. and M.R. Khan: Plant and soil nematodes associated with tuberose in West Bengal, India. Bangladesh J. Bot., 45, 1015-1025 (2016). 